Portland State University

PDXScholar

Environmental Science and Management

Faculty Publications and Presentations

10-1-1995

\title{
Intercomparison of Local Hydroxyl Measurements by Radiocarbon and FAGE Techniques
}

\author{
Malcolm J. Campbell \\ Washington State University \\ Brad D. Hall \\ Washington State University \\ John C. Sheppard \\ Washington State University \\ Philip L. Utley \\ Washington State University \\ Robert J. O'Brien \\ Portland State University
}

See next page for additional authors

Follow this and additional works at: https://pdxscholar.library.pdx.edu/esm_fac

Part of the Environmental Indicators and Impact Assessment Commons, and the Environmental Monitoring Commons

Let us know how access to this document benefits you.

\section{Citation Details}

M..J. Campbell, B.D. Hall, J.C. Sheppard, P.L. Utley, R.J. O'Brien, T.M. Hard and L.A. George, "Intercomparison of Local Hydroxyl Measurement by Radiocarbon FAGE Techniques", Journal of Atmospheric Sciences, 52, pp. 3421-3427, 1995.

This Article is brought to you for free and open access. It has been accepted for inclusion in Environmental Science and Management Faculty Publications and Presentations by an authorized administrator of PDXScholar. Please contact us if we can make this document more accessible: pdxscholar@pdx.edu. 


\section{Authors}

Malcolm J. Campbell, Brad D. Hall, John C. Sheppard, Philip L. Utley, Robert J. O'Brien, Thomas M. Hard, and Linda Acha George

This article is available at PDXScholar: https://pdxscholar.library.pdx.edu/esm_fac/7 


\title{
Intercomparison of Local Hydroxyl Measurements by Radiocarbon and FAGE Techniques
}

\author{
Malcolm J. Campbell and Brad D. Hall \\ Department of Civil and Environmental Engineering, Washington State University, Pullman, Washington \\ JOHN C. SHEPPARD \\ Department of Chemical Engineering, Washington State University, Pullman, Washington \\ PHILIP L. UTLEY* \\ Department of Civil and Environmental Engineering, Washington State University, Pullman, Washington \\ Robert J. O'Brien, Thomas M. Hard, and Linda A. George \\ Chemistry Department and Environmental Sciences Program, Portland State University, Portland, Oregon
}

(Manuscript received 4 October 1994, in final form 23 March 1995)

\section{ABSTRACT}

\begin{abstract}
A direct intercomparison of near-surface tropospheric HO concentration measurements by two different techniques was made in October-November 1992 at a rural site near Pullman, Washington. The atmosphere at the site is believed to contain low levels of anthropogenic pollution. The instruments' inlets were located at the same height $(3.5 \mathrm{~m})$ above the ground and were separated by $10 \mathrm{~m}$ along a line normal to the prevailing wind. Readings of the FAGE3 and radiocarbon instruments showed a high correlation $\left(r^{2}=0.74\right)$ despite HO concentrations that were frequently near the detection limit of the instruments. An unweighted least squares regression shows a slope significantly different from unity, indicating different calibration scales of the two instruments.
\end{abstract}

\section{Introduction}

The record of attempts to measure ambient hydroxyl (HO) radical concentrations in tropospheric air now extends over 20 years. A persistent skepticism remains about very challenging measurements, which will not abate until it has been demonstrated that congruent readings can be consistently obtained by instruments that employ different principles of operation.

The reliance upon congruent readings from collocated instruments reflects the short (less than $1 \mathrm{~s}$ ) chemical lifetime of the HO radical and its high probability of loss upon diffusive contact with solid surfaces. These two characteristics, combined with the large quantity of sample gas required by some techniques, preclude the use of conventional sample handling techniques at ambient pressures. This, in turn, has

* Current affiliation: Geophysical Institute, University of Alaska.

Corresponding author address: Dr. Malcolm J. Campbell, Department of Civil and Environmental Engineering, Washington State University, Pullman, WA 99164-2910. prevented the development of an accepted, reliable calibration method applicable to the variety of instruments in use.

A stringent intercomparison requires subjecting the instruments to both a wide range of atmospheric compositions (because of the possibility of fortuitous agreement as much as sensitivity to interfering species) as well as various wind speeds, directions, and turbulence (because of potential sensitivity to inlet region losses, which may be dependent upon the inlet flow regime). Neither this report nor the one clearly successful earlier report (Mount and Eisele 1992) pretend to describe a stringent test.

In this paper, we report on a direct intercomparison of two HO measurement techniques carried out at a clean-air site near Pullman, Washington, in October and November 1992.

\section{The intercomparison}

\section{a. The radiocarbon instrument}

The radiocarbon technique [Washington State University (WSU)] utilizes an ultraviolet (UV) -transparent flow reactor to observe the rate at which $\mathrm{CO}$ is 
oxidized by HO. Ambient air is drawn into the reactor, to which a small quantity of ${ }^{14} \mathrm{CO}$ is added, minimally perturbing the air within the reactor. A fraction of the ${ }^{14} \mathrm{CO}$ is oxidized to ${ }^{14} \mathrm{CO}_{2}$, which is then collected, purified to remove residual ${ }^{14} \mathrm{CO}$ and ${ }^{222} \mathrm{Rn}$, and subsequently analyzed for ${ }^{14} \mathrm{C}$ by gas-proportional counting. Detailed descriptions of the technique are available in Felton et al. (1988) and Felton et al. (1990).

The flow reactor has been extensively tested to demonstrate a lack of wall influence; that is, the walls do not contribute significantly to HO destruction or generation. The inlet region has also been studied and has shown negligible losses within a defined envelope of wind speed and attack angle. Ambient $\mathrm{HO}$ concentration is inferred from the concentrations of ${ }^{14} \mathrm{CO}_{2}$ and ${ }^{14} \mathrm{CO}$ within the reactor, the reaction time (the residence time of the flow reactor), and the $\mathrm{CO}-\mathrm{HO}$ rate constant. The method is absolute; there is no calibration procedure. The measurement depends (in absolute value) on the literature value for the $\mathrm{CO}-\mathrm{HO}$ rate constant, the collection efficiency for $\mathrm{CO}_{2}$, and accurate determination of the ${ }^{14} \mathrm{CO}$ concentration within the reactor.

Three aspects of the WSU system differ from those previously described. First, the results of recent measurements of the ${ }^{14} \mathrm{CO}_{2}$ collection efficiency differ from those previously reported. A collection efficiency of $0.63 \pm 0.01$ was used for this work, which is much higher than the previously reported value of 0.45 \pm 0.05 (Felton et al. 1990). The increase in collection efficiency is attributed to improvements in both the primary $\mathrm{CO}_{2}$ trap and the collection efficiency measurement procedure. Second, the flow rate of air drawn through the primary $\mathrm{CO}_{2}$ trap was decreased from 265 to $165 \mathrm{~cm}^{3} \mathrm{~s}^{-1}$ to minimize turbulence near the collection cone. The collection efficiency of $\mathrm{CO}_{2}$ was not affected by this flow reduction. Last, the daily average "background" signal (observed at night when the HO concentration is expected to be negligible) was subtracted from the WSU data. This method of data reduction results in a $2 \%-10 \%$ reduction in daytime $\mathrm{HO}$ concentration.

\section{b. The FAGE3 instrument}

The HO fluorescence instrument [Portland State University (PSU)] used in these experiments was as described by Chan et al. (1990), with only minor modifications to adapt it to a mobile laboratory. The number of parallel ambient air sampling channels feeding the fluorescence detection cell, formerly two, was increased to four. Each flow was admitted by a $0.8-\mathrm{mm}$ diameter nozzle into a cylindrical duct $(48 \mathrm{~mm}$ diameter), which continued through the detection cell to a manifold. The four nozzles were in a line perpendicular to the typical wind direction and $0.4 \mathrm{~m}$ above the roof of the mobile laboratory.

At the detection cell, circular openings in the air duct walls allowed passage of the single-pass laser beam through the air sample and collection of the resulting UV photon signals. As before, a fifth channel sampled a high-concentration HO source, used both to tune the laser wavelength for maximum spectral overlap and to normalize the detected ambient HO signals. The airflow rate in the latter "overlap" channel was less than half of that of each of the ambient channels. A valve between the overlap channel and the manifold was adjusted to prevent crosstalk with the nearest ambient $\mathrm{HO}$ channel.

The $\mathrm{Cu}$ vapor laser and the side-pumped, grazinggrating-tuned dye laser were unchanged from those of Chan et al. (1990). The outputs of the dye laser and frequency doubler were separated with a fused-silica equilateral prism. This prism also served to expand the UV beam in the direction parallel to the UV $\mathbf{E}$ vector in the plane defined by the excitation and detection axes, perpendicular to the air sample flow. The UV beam was collimated by a lens (focal length $0.5 \mathrm{~m}$ ), positioned so as to produce a nearly constant cross section $(1 \mathrm{~mm} \times 5 \mathrm{~mm})$ as the beam traversed the five detection zones. During the present experiments the UV linewidth was $0.3 \mathrm{~cm}^{-1}$; the available UV laser power ranged from $4.5 \mathrm{~mW}$ down to $0.5 \mathrm{~mW}$. During the last week of these experiments, the available UV laser power was less than $1 \mathrm{~mW}$.

The detector optical train was unchanged from that of Chan et al. (1990). Photon signals in all five channels were detected by Thorn EMI 9816 bialkali photomultipliers and further amplified. The four ambient HO channels were subjected to pulse-height discrimination. The resulting pulses from two of the ambient HO channels and the undiscriminated overlap channel were integrated by a gated counter in each channel. The gate period began $60 \mathrm{~ns}$ after the leading edge of scattering of the laser as detected at the counter and ended $300 \mathrm{~ns}$ later. Pulses from the remaining two ambient channels were integrated by NIM-compatible multichannel analyzers (LeCroy qvt3000) in time-correlated photon-counting mode; here the first $60 \mathrm{~ns}$ of the signal waveform was suppressed by vetoing the discriminator outputs. Since the gross photon arrival rate was much less than one per laser pulse, the signals in the timecorrelated channels were not degraded by photon pileup. The integrated signals (and waveforms, where applicable) were acquired by a computer for storage, interpretation, and graphic presentation. The computer controlled the switching of reagent between the carrier flows leading to injectors in the walls of the four ambient-sampling nozzles. The computer also automatically scanned and repositioned the laser wavelength drive at the peak of the $Q_{1}(2)$ HO line using the signal from the overlap channel.

The cell pressure was maintained at 4.5 torr by a 300 cfm pump (Roots). Periodic addition of isobutane to the sampled ambient airflow was used to remove $90 \%$ of its ambient $\mathrm{HO}$ in order to measure the non-HO background by chemical modulation, as in Hard et al. 
(1984, 1992). From time to time, the background thus measured was compared with that obtained by tuning the laser away from the $\mathrm{HO}$ excitation line (spectral modulation), to verify the absence of photolytic HO signals.

FAGE3 suffered from poor signal-to-noise ratios during the intercomparison, which required us to use signal averaging times typically $0.5-1.0 \mathrm{~h}$, similar to those required for FAGE2, rather than the much shorter averaging times obtained by Chan et al. (1990) under laboratory conditions. The poor sensitivity was due to low available laser power during the days when both instruments were recording data and to a red shift of the passband of the interference filters used to separate the $\mathrm{HO}$ emission near $309 \mathrm{~nm}$ from ambient and scattered light, perhaps brought on by previous exposure to high temperatures. This red shift resulted in very little of the HO fluorescence reaching the photomultipliers. Unfortunately, the interference filter failure was identified only after the Pullman experiments were completed.

Calibration of the response to external HO was achieved by sampling air from a UV-irradiated, continuously stirred tank reactor made of Teflon FEP film, in which the HO concentration was measured simultaneously via the loss rate of a hydrocarbon that reacts with HO (Hard et al. 1984, 1992). Mesitylene (1,3,5trimethylbenzene) vapor, NO, and water vapor were added to a flow of hydrocarbon-free air that was sufficient to supply the four FAGE3 nozzles and other outflows from the chamber. The chamber contents were stirred by a small fan. The mesitylene concentration was measured alternately in the inflow and outflow of the chamber, using a 10-port valve with two sample loops, a heated Porapak column, and a photoionization detector with a $10.7 \mathrm{eV}$ lamp. A computer was used to switch the valve, record the ion signal, integrate the chromatographic peaks, and plot and record the peak areas and derived $\mathrm{HO}$ concentrations. One pair of inflow-outflow measurements was made every $30 \mathrm{~s}$. At steady state the HO concentrations are given by

$$
[\mathrm{HO}]=\left(\frac{[\mathrm{HC}]_{i}}{[\mathrm{HC}]_{o}}-1\right) / \tau k,
$$

where $k$ is the rate coefficient for the reaction of $\mathrm{HO}$ and mesitylene (HC) $\left[6 \times 10^{-11} \mathrm{~cm}^{3} \mathrm{~mol}^{-1} \mathrm{~s}^{-1}\right.$ (Perry et al. 1977)], $\tau$ is the chamber residence time (measured by the decay of an unreactive species), and $[\mathrm{HC}]_{i}$ and $[\mathrm{HC}]_{o}$ are the concentrations of mesitylene in the inflow and outflow, respectively.

\section{c. Site description}

The site chosen for the intercomparison was about 5 $\mathrm{km}$ north of Pullman, Washington, (population 25000 ) at a U.S. Department of Agriculture Land Management and Soil Conservation research station. The area within
$200 \mathrm{~km}$ is devoted to agriculture or forestry, with low population densities except for the Spokane urban area $120 \mathrm{~km}$ to the north. Within the quadrant of prevailing wind, the nearest urban areas are Richland-Kennewick, Washington, (about $220 \mathrm{~km}$ ) and Portland, Oregon, $(500 \mathrm{~km})$. Measurements made over several years at similar sites near Pullman have shown continental background concentrations of chlorofluorocarbons more than $99 \%$ of the time (Carter et al. 1983). The area in the immediate vicinity, and to the west for a considerable distance, is devoted to dry-land crops (primarily wheat). Thus, we expect the chemical composition of the air to be close to that of clean, continental air, except for modest elevations of $\mathrm{NO}_{x}$ due to the use of nitrogen fertilizers (mostly anhydrous ammonia). We also expect the composition to remain constant (i.e., reflect the long periods available for mixing) except for events caused by rare local traffic or fluctuations in wind direction. Wind directions of SSE would put the site in the plume of Pullman or Moscow, Idaho, $(15 \mathrm{~km})$, a city of similar size. The site was a compromise between the desire for slowly varying atmospheric composition and the need for three-phase electrical power.

The instruments were located $10 \mathrm{~m}$ apart, in a line perpendicular to the prevailing wind (WSW), which predominated during less than half of the intercomparison period. The instrument site (Fig. 1) was located in the lee of a saddle and two small hills, and upwind of a small workshop and storage building.

The FAGE instrument was mounted in a motor home, with its inlets located about $1 \mathrm{~m}$ from the rear edge of the roof. The motor home was parked facing north with the inlets positioned near the south end of the motor home in a line running NW-SE. The radiocarbon instrument was positioned $10 \mathrm{~m}$ to the south of the motor home on a 2-m open scaffold such that the inlet was located at the same height as the FAGE inlet $(3.5 \mathrm{~m})$.

Wind speed and direction (at $3.5 \mathrm{~m}$ ), temperature, relative humidity, ozone, and solar radiation were monitored. Wind speed and direction were measured with a trivane anemometer (R. M. Young). Ozone was measured with a Dasibi ozone sensor (model 1003-AH). Solar radiation was monitored with an ultraviolet actinic radiometer (model IL 730A, International Light) directed vertically upward. The radiometer closely approximates the spectral weighting required to measure the $\mathrm{O}_{3}$ photolysis rate $\left(J_{\mathrm{O}\left({ }^{\prime} \mathrm{D}\right)}\right)$ but has a Lambertian angular response.

\section{Results and discussion}

Concurrent HO measurements were made on six days beginning on 27 October 1992. Because of delays in starting the campaign, HO concentrations were lower than desirable, frequently near the detection limits of the instruments. Nevertheless, we thought it important to 


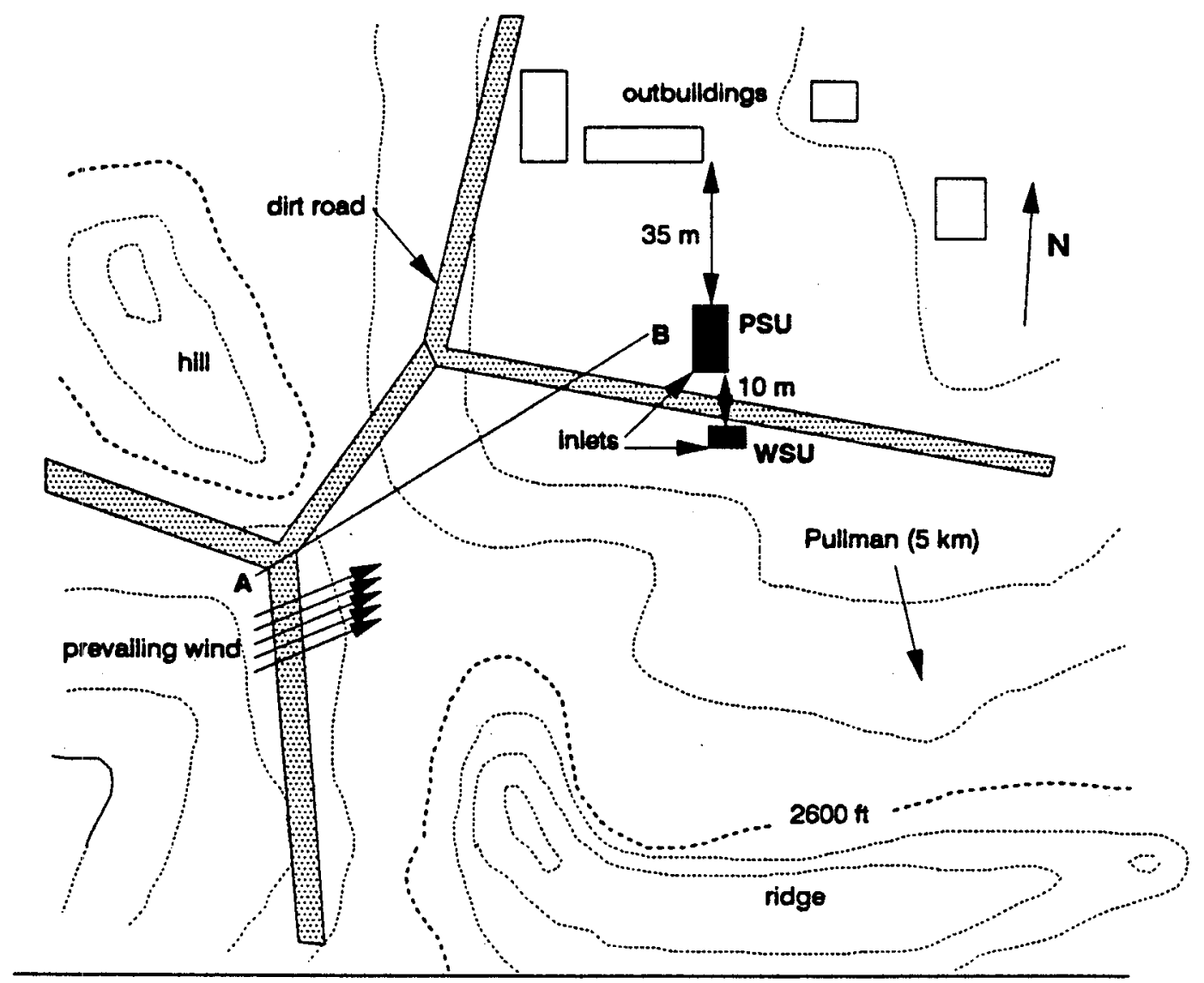

FIG. 1. Schematic of the site showing position of WSU and PSU instruments. Contour lines are not exact but indicate the general features of the surrounding terrain. (Contour interval is $20 \mathrm{ft}$.) Diagram is not to scale. Distance A-B is approximately $200 \mathrm{~m}$.

collect data over a wide range of conditions. The FAGE instrument recorded continuous data, normally starting in the morning, while the radiocarbon instrument measured from near local noon to after sunset.

The records of $\mathrm{HO}, \mathrm{O}_{3}$, solar radiation, and wind speed and direction are shown in Fig. 2. The expected correlation between $\mathrm{HO}$ and solar intensity is, for the most part, evident, with no obvious correlation with the other variables. The data for comparison are shown in Table 1 and in Fig. 3. Two data points were excluded because they were more than three standard deviations distant from a trial least squares regression. The least squares regression of the remaining 22 pairs of $\mathrm{HO}$ measurements is shown in Fig. 3 (solid line). The correlation coefficient $\left(r^{2}=0.74\right)$ is encouragingly high despite many measurements made near the detection limit of one or both instruments.

The $y$-intercept estimate of $0.93 \times 10^{6} \mathrm{~cm}^{-3}$ (corresponding to $-0.32 \times 10^{6} \mathrm{~cm}^{-3}$ from the PSU instrument ) is statistically significant on the basis of the usual $t$ test. However, the assumptions of this test include zero variance in the $x$ data and equal variance in the $y$ data. These assumptions are strongly violated in this case. It should also be noted that the data that largely determine the intercept include measurements made at night or under low-light conditions when ambient $\mathrm{HO}$ concentrations are expected to be very low. During these times, the relative uncertainties of the instruments are large and the readings are often not significantly different from zero. A weighted regression analysis (Smillie 1966) in which the data were weighted by the inverse of their estimated relative variances gives similar estimates of the parameters but with a nonsignificant intercept.

The regression line displays a slope (WSU/PSU $=2.9$ ) that is significantly higher than unity. This indicates that the two instruments, independently calibrated, either are not sampling the same $\mathrm{HO}$ concentration or have a calibration discrepancy. The cause of the disagreement is not clear to the investigators. Here we discuss some potential causes and the impact of each.

First, it is possible that the two instruments were sampling airstreams of different HO concentration since the measurements were not precisely collocated 

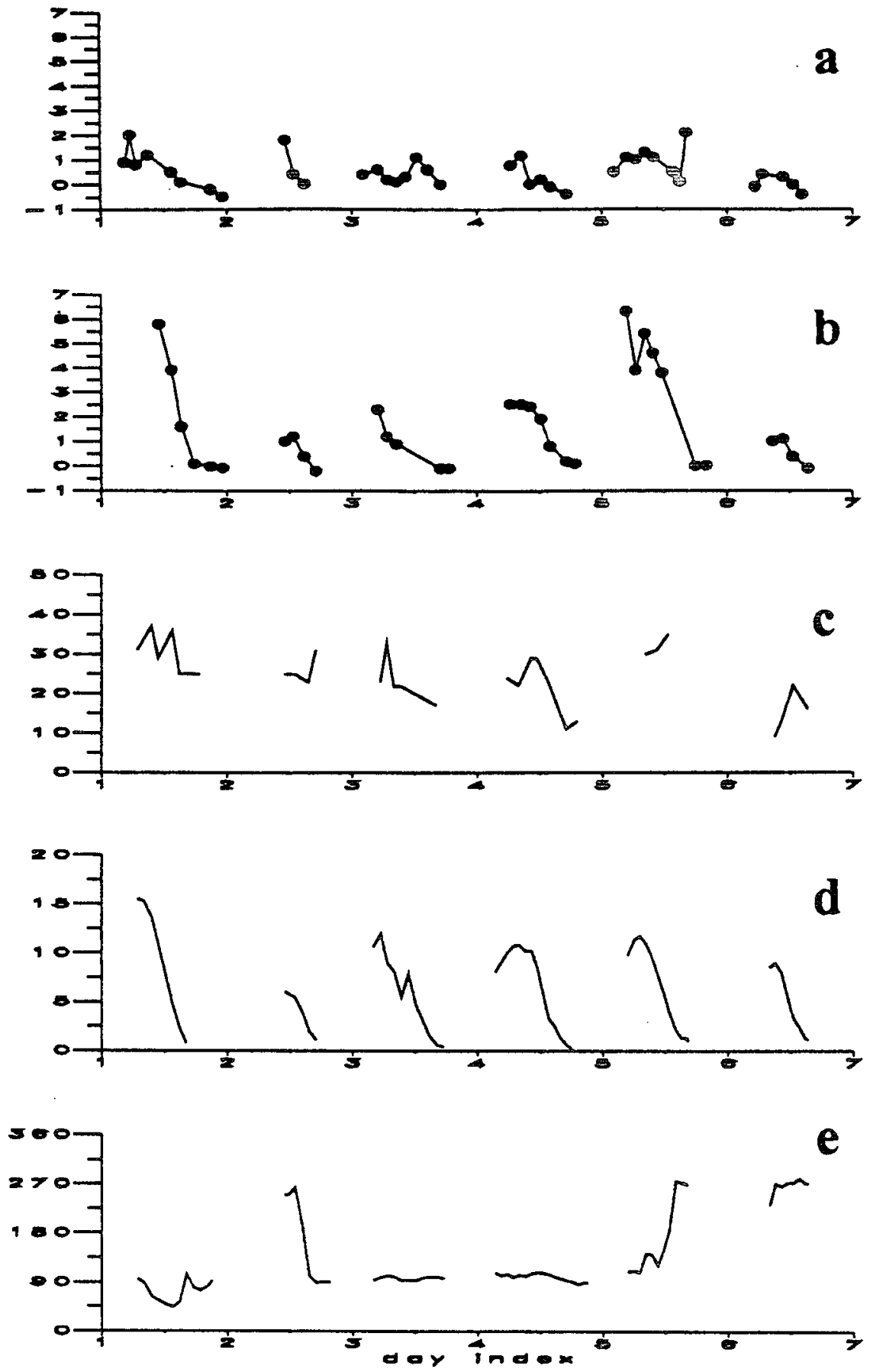

FIG. 2. Time series of (a) PSU and (b) WSU HO measurements $\left(10^{6} \mathrm{~cm}^{-3}\right)$, (c) ozone (ppb), (d) solar radiation, and (e) wind direction (degrees). The abscissa represents a sequence of six days ( 27 Oct, 5 Nov, 6 Nov, 13 Nov, 14 Nov, and 15 Nov). A total of 12 hours are shown each day ( 0800 to 2000 ); thus, the midpoint of each section marks 1400 . All valid HO data collected during the 6-day campaign are shown. Not all of these data are included in the intercomparison, however, as both groups did not make corresponding measurements at all times. Solar radiation, as shown, is approximately the ozone photolysis rate $\left(J_{\left.\mathrm{O}^{\prime} \mathrm{D}\right)}\right)$, in arbitrary units (see text). 
TABLE 1. Summary of the 22 pairs of WSU and PSU HO measurements used in the intercomparison. Columns from left: month, day, time, sample (1: daytime, 0: nighttime background), WSU HO and one standard deviation, and PSU HO and one standard deviation (HO concentrations are $10^{6} \mathrm{~cm}^{-3}$ )

\begin{tabular}{|c|c|c|c|c|c|c|c|}
\hline mo & d & Time (PST) & C & WSU & Std dev & PSU & Std dev \\
\hline 10 & 27 & 1442 & 1 & 3.9 & 0.5 & 0.5 & 0.5 \\
\hline 10 & 27 & 1536 & 1 & 1.6 & 0.3 & 0.1 & 0.6 \\
\hline 10 & 27 & 1827 & 0 & 0.0 & 0.1 & -0.2 & 0.3 \\
\hline 10 & 27 & 1935 & 0 & -0.1 & 0.1 & -0.5 & 0.5 \\
\hline 11 & 5 & 1424 & 1 & 1.2 & 0.3 & 0.4 & 0.6 \\
\hline 11 & 5 & 1525 & 1 & 0.4 & 0.2 & 0.0 & 0.6 \\
\hline 11 & 6 & 1033 & 1 & 2.3 & 0.5 & 0.6 & 0.6 \\
\hline 11 & 6 & 1126 & 1 & 1.2 & 0.3 & 0.2 & 0.7 \\
\hline 11 & 6 & 1220 & 1 & 0.9 & 0.2 & 0.1 & 0.6 \\
\hline 11 & 6 & 1629 & 0 & -0.1 & 0.1 & 0.0 & 0.5 \\
\hline 11 & 13 & 1116 & 1 & 2.5 & 0.6 & 0.8 & 0.8 \\
\hline 11 & 13 & 1216 & 1 & 2.5 & 0.6 & 1.2 & 0.4 \\
\hline 11 & 13 & 1307 & 1 & 2.4 & 0.5 & 0.0 & 0.7 \\
\hline 11 & 13 & 1408 & 1 & 1.9 & 0.4 & 0.2 & 0.6 \\
\hline 11 & 13 & 1502 & 1 & 0.8 & 0.2 & -0.1 & 0.7 \\
\hline 11 & 13 & 1636 & 0 & 0.2 & 0.2 & -0.4 & 0.7 \\
\hline 11 & 14 & 1022 & 1 & 6.3 & 1.3 & 1.1 & 0.4 \\
\hline 11 & 14 & 1115 & 1 & 3.9 & 0.8 & 1.0 & 0.4 \\
\hline 11 & 14 & 1208 & 1 & 5.4 & 1.1 & 1.3 & 0.6 \\
\hline 11 & 14 & 1255 & 1 & 4.6 & 0.9 & 1.1 & 0.6 \\
\hline 11 & 15 & 1320 & 1 & 1.1 & 0.3 & 0.3 & 0.5 \\
\hline 11 & 15 & 1418 & 1 & 0.4 & 0.2 & 0.0 & 0.3 \\
\hline
\end{tabular}

in space and time. Each radiocarbon sample was collected over a 90 -s time interval. Continuous FAGE data were averaged for 45-minute periods centered on the

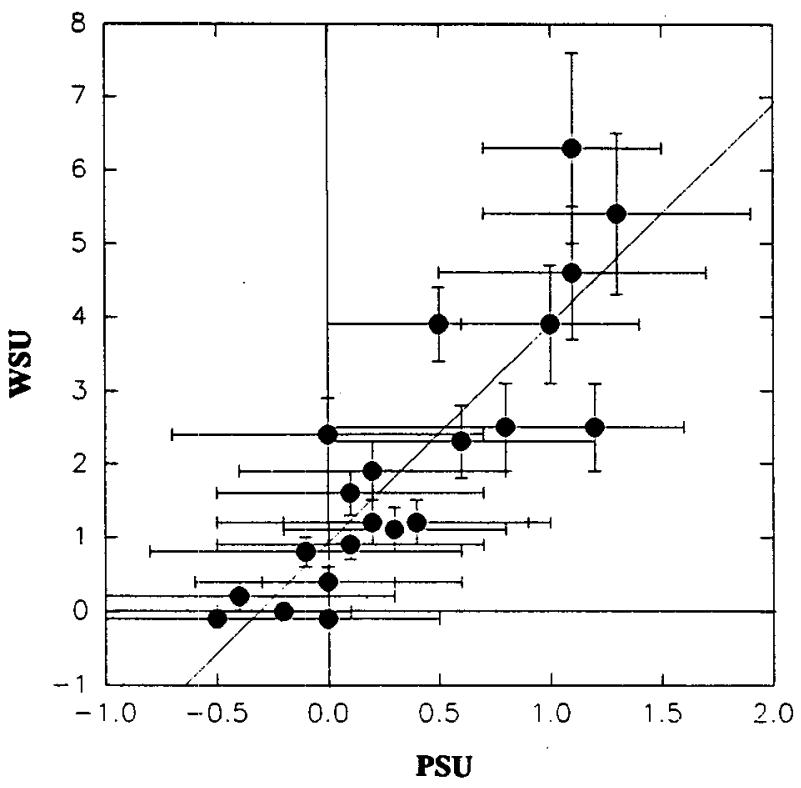

FIG. 3. Comparison of WSU and PSU HO measurements $\left(10^{6} \mathrm{~cm}^{-3}\right)$. The solid line represents an unweighted least squares fit to the 22 data pairs. Error bars are one standard error. radiocarbon sample. Perturbations much shorter than the 45-min FAGE averaging period would lose significance in the FAGE average but could play a more significant role in the radiocarbon $\mathrm{HO}$ determination. Although no such perturbations were known to arise, we were not fully prepared to recognize such events.

We cannot rule out differential inlet-region losses, which would be relatively constant in time, but these seem unlikely. The PSU instrument is calibrated in situ, including the inlet, although under somewhat different flow conditions. In addition, we took the precaution of raising the PSU inlet height from 0.2 to $0.4 \mathrm{~m}$ above the roof of the PSU mobile laboratory. This was done to reduce the risk of $\mathrm{HO}$ loss to the roof of the motor home, although no significant change in measured HO concentration was observed following inlet relocation. It is possible that all or some of the other factors mentioned may have influenced the local HO field, although there is little evidence to suggest an excess variation due to a variable $\mathrm{HO}$ field. We cannot rule out that possibility, however, since few data were collected under ideal conditions (i.e., high temperature and humidity, clear skies, steady SW wind).

The observed discrepancy could be due to the WSU instrument producing readings above the true $\mathrm{HO}$ concentration. WSU has investigated possible causes for such an effect without success. The instrument recorded consistently low background (i.e., nighttime) readings $\left[0.3( \pm 0.3) \times 10^{6} \mathrm{~cm}^{-3}\right]$ throughout the ex- 


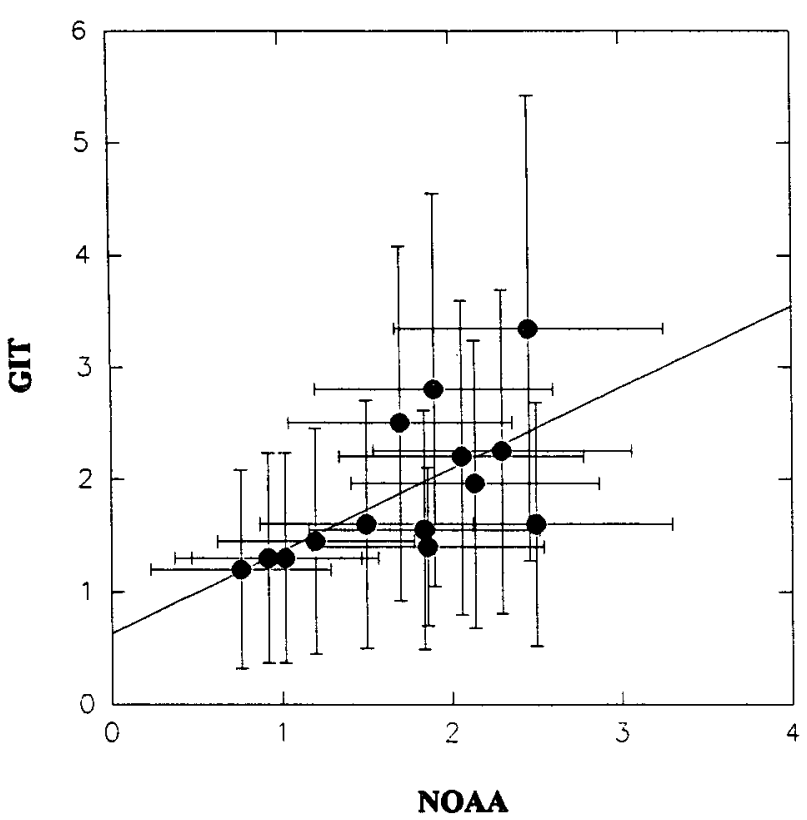

FIG. 4. Comparison of NOAA (National Oceanic and Atmospheric Administration) and GIT (Georgia Institute of Technology) HO measurements, from Mount and Eisele (1993); error bars are one standard error, solid line is unweighted least squares fit.

periment; thus, a higher than predicted sensitivity can only result from excess production of ${ }^{14} \mathrm{CO}_{2}$ by some process that occurs only during the daytime or by an underestimation of the ${ }^{14} \mathrm{CO}$ concentration employed. The latter question has been investigated by several techniques, revealing no errors.

Correspondingly, the PSU calibration could produce a reading below the true value. Subsequent to the Pullman intercomparison, the PSU group has carried out an extensive check of their calibration procedures against new, independent techniques for generating known HO concentrations and find no reason to disbelieve the traditional CSTR tracer calibration. These results will be published elsewhere.

A final hypothesis is that the experimental imprecisions may mask any perceived calibration agreement or disagreement. The formal imprecision of the data is shown in Table 1 and Fig. 3. The imprecisions represent the standard errors of the data but do not include the uncertainties from the calibration procedure in the PSU case or the $\mathrm{CO}-\mathrm{HO}$ rate constant in the WSU case. We do not discount the possibility of a real discrepancy but we believe that the observed discrepancy may be, at least in part, a consequence of a lack of data collected during ideal conditions.

This hypothesis leads to a concluding note on $\mathrm{HO}$ intercomparisons. The two $\mathrm{HO}$ intercomparisons to date are shown in Figs. 3 and 4, the latter employing data from Mount and Eisele (1992) in a linear regression format. It is clear that obtaining either a definitive correlation or a precise estimate of relative calibration requires very large quantities of data, unless the signalto-noise ratio for the instruments is high for much of the time. For the present instruments, the following improvements are needed: the instrumental sensitivities of FAGE3 should be improved (replacing the defective interference filters has made a large difference) and the sample frequency of the radiocarbon method should be increased. Alternatively, carrying out the intercomparison earlier in the summer in better weather conditions would ensure reliably higher HO concentrations.

An ideal intercomparison will aim to collocate the instruments to the maximum extent. In particular, it must address losses of HO and progenitor radicals to surrounding surfaces, a potential contributor to both offset and variance. It should, at least in the immediate future, be conducted at a site selected for high prevailing HO concentrations with minimal variations in space and time (at least within the timescales of the measurements). This means a remote site, perhaps with modestly elevated $\mathrm{NO}_{x}$ but low hydrocarbon concentrations. Last, concurrent measurement of all key species involved in photochemistry would be desirable in order to characterize air masses and identify periods of rapidly changing composition. This would provide insight into potential instrument discrepancies and our understanding of photochemistry.

Acknowledgments. We are grateful to the National Science Foundation for Grants ATM 8900058 (M.J.C) and ATM 8615163 (R.J.O), which supported this work, and to R. I. Papendick and Alex G. Ogg Jr. of USDA/ARS for permission to use the site. The PSU group thanks the WSU group, and especially M.J.C., for their hospitality during the time spent in Pullman.

\section{REFERENCES}

Carter, M. W., D. R. Cronn, W. L. Bamesberger, and E. Robinson, 1983: Halocarbon concentration patterns associated with frontal passages. Geophys. Res. Lett., 10(11), 1100-1103.

Chan, C. Y., T. M. Hard, A. A. Mehrabzadeh, L. A. George, and R. J. O'Brien, 1990: Third-generation FAGE instrument for tropospheric hydroxyl measurements. J. Geophys. Res., 95, $18569-18576$.

Felton, C. C., J. C. Sheppard, and M. J. Campbell, 1988: Measurements of the diurnal $\mathrm{OH}$ cycle by a ${ }^{14} \mathrm{C}$-tracer method. Nature, 335(6185), 53-55.

$\longrightarrow,-$, and -1990 : The radiochemical hydroxyl radical measurement method. Environ. Sci. Technol., 24(12), 1841-1847.

Hard, T. M., R. J. O'Brien, C. Y. Chan, and A. A. Mehrabzadeh, 1984: Tropospheric free radical determination by FAGE. Environ. Sci. Technol., 18, 768-777.

—- A. A. Mehrabzadeh, C. Y. Chan, and R. J. O'Brien, 1992: FAGE measurements of tropospheric $\mathrm{HO}$ with measurements and model of interferences. J. Geophys. Res., 97, 9795-9817.

Mount, G. H., and F. L. Eisele, 1992: An intercomparison of tropospheric $\mathrm{OH}$ measurements at Fritz Peak Observatory, Colorado. Science, 256, 1187-1189.

Perry, R. A., R. Atkinson, and J. N. Pitts Jr., 1977: Kinetics and mechanism of the gas phase reaction of $\mathrm{OH}$ radicals with aromatic hydrocarbons over the temperature range $296-473 \mathrm{~K} . J$. Phys. Chem., 81, 296-304.

Smillie, K. W., 1966: Introduction to Regression and Correlation. Academic Press, p. 99. 